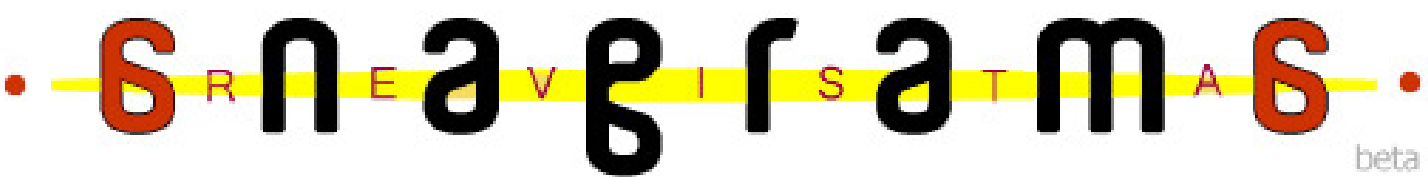

\section{Os blogs como instrumentos de prestação de contas na esfera pública interconectada: o blog da deputada federal manuela D’Áuila}

\author{
Gabriela Assmann ${ }^{1}$ \\ Rejane de Oliveira Pozobon²
}

\section{RESUMO}

O presente trabalho pretende abordar as mudanças que as relações dos sujeitos, especificamente no âmbito político, sofrem na nova configuração da esfera pública e verificar de que forma os blogs podem ser utilizados como instrumentos de prestação de contas, contribuindo para estas mudanças e para a efetivação do que chamamos de esfera pública interconectada. Para isso, analisaremos, através da metodologia de análise de conteúdo, o caso do blog da Deputada Manuela D’Ávila (PCdoB - RS), em especial três postagens referentes às declarações do Deputado Jair Bolsonaro (PP - RJ) ao Programa CQC - Custe o Que Custar - da Rede Bandeirantes.

Palauras-chaue: esfera pública interconectada; prestação de contas; política.

\section{Considerações iniciais}

A concepção de esfera pública que temos hoje foi sendo construída e profundamente modificada no decorrer da história. Sabendo disso, é essencial que se estude essa mudança e as formas de participação dos sujeitos nessa esfera. Mudanças como o surgimento da internet e das redes sociais digitais possibilitam novas formas de interação, além de tornar a comunicação mais ágil e com um custo menor.

Se utilizando desse benefício, muitos serviços têm sido ofertados pela internet, como forma de reduzir custos e acelerar processos. Não seria diferente na instância da política, na qual os políticos cada vez mais se utilizam destas redes para prestar contas dos mandatos.

\footnotetext{
${ }^{1}$ Acadêmica do sétimo semestre do Curso de Relações Públicas na Universidade Federal de Santa Maria. Email: gabiassmann@gmail.com

2 Professora do Programa de Pós Graduação em Comunicação e do Departamento de Ciências da Comunicação da Universidade Federal de Santa Maria. Doutora em Ciências da Comunicação. E-mail: rejane.op@terra.com.br
} 
Através de atividades de observação percebemos que a Deputada Federal Manuela D’ávila (PCdoB - RS) faz uso da internet e das redes sociais digitais como ferramentas de prestação de contas do mandato, dialogando com seus públicos, principalmente através do blog (www.bolademeiaboladegude.blogspot.com).

Neste texto, objetivamos apresentar algumas considerações, a partir da análise de dados empíricos coletados no referido blog.

\section{A esfera pública interconectada}

Os primeiros teóricos que conceituaram o espaço público falavam sobre um espaço físico, onde os cidadãos pudessem interagir. Um bom exemplo desses espaços seriam as assembléias realizadas em praça pública na Grécia Antiga. Habermas (2003) acreditava que esse espaço servia como mediação entre o estado e a sociedade civil, na qual se incluíam apenas os cidadãos. Para ser considerado cidadão era necessário ser homem, nascido na Grécia e filho de pai e mãe que também tivessem o mesmo status de cidadãos. Além disso, era preciso possuir um nível socioeconômico que garantisse acesso à educação. Portanto, apesar da Grécia ser considerada o berço da democracia, sabemos que esta era bastante limitada naquela sociedade.

Posteriormente este modelo foi bastante criticado por diversos pesquisadores, o que levou o próprio autor a revê-lo, três décadas após sua proposição. Atualmente, Habermas acredita na existência de múltiplas esferas públicas, que não necessariamente ficam restritas a espaços institucionalizados que permitam o debate público, como o parlamento.

Em suas formulações mais recentes, Habermas $(1992,1997)$ revisa sua concepção original de esfera pública e propõe a existência de uma variedade de esferas públicas - nas quais os sujeitos estão permanentemente reestruturando suas relações, palco para discussões, debates e questões sociais de relevância, que são trazidos à tona por indivíduos ou coletividades, minorias ou maiorias, atores ou espectadores. (BARICHELLO, 2003 p. 65)

Hoje, sabemos que estamos imersos em uma esfera pública midiatizada, fato que transforma as relações dos sujeitos com o meio. Instâncias que antes eram privadas agora são públicas. Um bom exemplo desse fenômeno são os reality shows, que invadem a vida privada dos indivíduos em seus mais diversos aspectos, e dessa forma, conquistam 
enormes índices de audiência e grandes cotas de patrocínio, comprovando o sucesso destas novas formas de exposição.

As tecnologias de informação e comunicação estão cada vez menores e mais acessíveis, possibilitando que um fato inesperado possa ser filmado com um celular, por um cinegrafista amador que depois colocará as imagens na internet, ou as cederá para a grande mídia. Câmeras de segurança colocadas nas ruas nos fazem viver em um grande observatório. A midiatização invade diversas instâncias da vida humana.

Esse processo transforma a sociedade de forma que para ser visto e ter legitimidade é necessário estar presente na grande mídia, pois é através dela que a maior parte da população tem acesso a informação.

Atualmente, é através dos meios de comunicação que acontece a formação da opinião pública, uma vez que é por meio deles que os acontecimentos obtêm visibilidade, proporcionando a discussão sobre as questões que circulam na mídia em todas as esferas da sociedade. (BARICHELLO 2003, p. 61)

Porém, essa esfera pública midiatizada é perpassada por inúmeras mediações, dentre as quais podemos destacar: a linha editorial do veículo, as limitações tecnológicas do meio através do qual a mensagem será veiculada, além, é claro, das mediações proporcionadas pelo repertório de cada pessoa que receber o conteúdo propagado pelos media.

Por conta da dificuldade de ser ator e sujeito de transformação nos grandes meios de comunicação, muitas pessoas tem se utilizado da internet na tentativa de ter voz e de ser ouvido por muitos, com pouco custo, não importando distâncias geográficas.

Pode-se pensar a internet como um espaço que se configura no que chamamos hoje de "esfera pública interconectada" (Benkler apud Silva 2006), ou seja, um conjunto de práticas informais usadas pelas pessoas para debater questões de interesse público, mas que só podem ser resolvidas se contarem com a ação coletiva.

A esfera pública interconectada não é feita de ferramentas, mas das práticas de produção social que essas ferramentas possibilitam. O efeito primário da internet na esfera pública em sociedades liberais recai na produção informacional de atores de fora do mercado: o trabalho de indivíduos sozinhos e em cooperação com outros, ou de associações formais como ONGs, bem como o retorno do seu efeito sobre a mídia tradicional. (BENKLER apud SILVA, 2010, p. 53) 
Esta esfera pública interconectada complementa debates e discussões que ocorrem em outras esferas. Através das ferramentas digitais é possível debater sobre os mais diversos aspectos da vida pública, fazendo com que ressurja o que Gomes (2005) chama de "esperanças de modelos alternativos de democracia". Para ele, a democracia representativa está em crise, e o modelo que a confronta é o de democracia direta, que já foi vencida por se mostrar inadequada para a sociedade de massa e para a complexidade do Estado contemporâneo. Neste contexto, é necessário que surjam modelos alternativos de democracia, que possam ser uma via entre a democracia representativa (que retira o poder do cidadão) e a democracia direta (que oferta ao cidadão todo o poder).

O principal modelo apontado por Gomes é o da democracia deliberativa, que se caracteriza por dar o poder de decisão aos cidadãos através de um processo de deliberação livre entre cidadãos considerados iguais moral e politicamente. Se formos analisar, este modelo pode se parecer com o da Grécia Antiga, porém, as possibilidades comunicacionais que as tecnologias nos apresentam, trazem novas ideias a este processo de deliberação. A internet é uma facilitadora da participação dos sujeitos nos debates, tendo em vista que possibilita uma relação sem intermediários entre a esfera civil e a esfera política. O processo decisório se dá praticamente da mesma maneira, a diferença é a quantidade de pessoas que podem participar deste processo hoje.

\section{Rumo à quarta reuolução comunicatiua}

Até hoje vivemos três grandes revoluções comunicativas, assim conhecidas por impactar toda sociedade e por introduzir novas possibilidades de comunicação, modificando as formas como o ser humano socializa e interage com o ambiente. Cada uma destas revoluções introduziu um novo meio capaz de impactar cada vez mais pessoas em menor tempo e com menos custos. Estas revoluções continuam impactando na sociedade, mesmo tanto tempo depois de ocorridas.

A primeira foi a revolução quirográfica ou revolução da escrita, que ocorreu no século $\mathrm{V}$ a.C e foi marcada pela passagem da cultura oral para a cultura escrita. As primeiras formas de escrita foram a suméria, a cuneiforme e os hieróglifos egípcios. Com a escrita surge a possibilidade de armazenar conhecimentos e guardá-los para a posteridade, deixando um legado para as gerações futuras. 
Esta revolução tem grande relevância, por ser primeira e também por intrigar o ser humano até hoje. Podemos encontrar escritos pré-históricos em uma caverna e não conseguir decifrá-los. Cada nova forma de escrita descoberta ajuda a decifrar a história, a desvendar algo novo a respeito da humanidade.

A segunda revolução foi a de Gutemberg, ocorrida na metade do século $\mathrm{XV}$, com a invenção da prensa de tipos móveis, que possibilitava a impressão de forma mais rápida, fazendo as ideias circularem através das primeiras publicações, levando ao surgimento da incipiente imprensa. Essa revolução comunicativa teve ligação direta com a Reforma Protestante, modificando, dessa forma, a sociedade européia da época.

A possibilidade de imprimir panfletos, jornais e outros veículos fez com que as ideias protestantes, em especial as 95 teses, circulassem de maneira mais rápida. Já a possibilidade de imprimir exemplares da Bíblia fez com que mais pessoas pudessem ter acesso a ela, gerando dessa forma novas interpretações, que não passavam pela mediação dos padres. Este foi o primeiro episódio da história em que a imprensa teve papel fundamental.

Com a invenção de meios como o telégrafo, o rádio e a televisão, aconteceu a revolução elétrica, marcada entre os séculos XIX e XX. Nessa época começou a cultura de massa, com a difusão cada vez maior das mensagens, através desses novos meios eletrônicos.

A um olhar histórico, a relação entre mídia, tecnologia de comunicação e participação pública resulta mais facilmente compreensível. Além de mudar as opiniões e as formas de interagir, a introdução de um novo meio de comunicação e de uma nova tecnologia comunicativa, num determinado momento da história da humanidade, passou a atingir a esfera da interação com o mundo, contribuindo para determinar a transformação da estrutura de percepção da realidade. (DI FELICE, 2008 p. 21)

Levando em conta as características das três revoluções anteriores, Di Felice (2008) considera que estejamos vivendo a quarta revolução - a da comunicação digital. Como já dito anteriormente, a internet e as redes sociais digitais trazem à tona novas possibilidades de conversação e novos fluxos comunicacionais, não sendo somente um fluxo de um para muitos, como nos meios de comunicação de massa, mas sim, fluxos variados, como de muitos para um. 
$\mathrm{O}$ advento destas tecnologias resulta em mudanças significativas em diversos âmbitos da vida humana, como as possibilidades de sociabilidade, de lazer, de cultura, mercadológicas, como sites de e-commerce e até na instância política, possibilitando transparência e diálogo através da democratização das informações.

"As instituições mais potentes do mundo, como o Congresso e o governo norteamericano, são também as mais transparentes na web". O efeito da internet, segundo o filósofo tunisiano, é precisamente aquele de dar vida a tal "transparência" nos atos do Estado e das grandes empresas (...). (KERCHOVE, 2008 p. 128 e 129$)$

Diante de tamanhas mudanças não é possível que o ser humano fique estagnado, sem buscar inovar, desde suas atividades mais cotidianas até as atividades profissionais. Não são as tecnologias sozinhas que causarão mudanças, mas sim, o uso que faremos delas, as apropriações que daremos para cada nova possibilidade de comunicação. Percebendo esse fenômeno muitas entidades, coletivas ou individuais, optam por utilizar a internet como forma de se comunicar com os públicos de interesse, criando, muitas vezes, estratégias que busquem otimizar as possibilidades e reduzir os riscos.

\section{Os blogs e a blogosfera}

Os blogs são páginas da web que permitem postagens em ordem cronológica, tem semelhança com um diário e possuem espaço para comentários dos leitores. Como vemos em Terra, 2008, blog é uma contração da palavra de origem inglesa "Weblog", que é a junção de "Web" (página da internet) e "Log" (diário de bordo). Inicialmente, os blogs eram muito utilizados como modernos diários, através dos quais as pessoas relatavam seu cotidiano, desabafavam ou escreviam poemas. Hoje são muito mais do que isso.

As ferramentas gratuitas para criação de blogs facilitaram muito o processo de expansão desta tecnologia, tornando-os acessíveis a qualquer pessoa que possua acesso a internet. Além disso, a facilidade de manutenção de um blog é outro fator que colabora com esse crescimento. Segundo dados de 2010 do MidiaBoom existem aproximadamente 150 milhões de blogs no mundo. São esses blogs e as redes criadas entre os blogueiros que formam um sistema complexo e dinâmico, conhecido como blogosfera. 
Em uma era onde muito se fala de cultura participativa e de "convergência" (Jenkins, 2006) esses usos se ampliaram e o blog hoje é uma poderosa ferramenta de comunicação que se consolida cada vez mais, tanto na mente dos atores quanto dos espectadores.

Enquanto assiste ou lê a uma matéria sobre política no jornal, um jovem mais engajado pode tuítar a respeito. Depois, pode procurar na internet maiores informações a respeito daquele fato, ou do político protagonista de tal fato. Cidadãos que antes eram passivos e isolados agora são ativos, já que a circulação de conteúdos nessa era de convergência dá-se devido à participação dos cidadãos. Convergência não pode ser entendida apenas como um fenômeno tecnológico, como o smartphone, mas sim um fenômeno social. É aí que os blogs assumem importância nessa nova conjuntura.

Eles são ótimos exemplos de cultura participativa, tendo em vista que agregam as características necessárias para isso: são tecnologias digitais acessíveis (plataformas gratuitas), tem conteúdo gerado pelo usuário e alteram as relações de poder entre os segmentos de mercado de mídia e seus consumidores.

Outra vantagem que os blogs possuem em relação aos meios de comunicação tradicionais e massivos é a possibilidade de interação, mesmo que mediada por computador (Primo, 2007). Segundo o autor, a maior parte das interações que ocorrem no ciberespaço não são plenas, portanto são reativas, segundo a categorização proposta por ele. Essas interações são pouco livres e ocorrem a partir de determinadas condições iniciais, de um estímulo, visando atingir um objetivo pré-determinado. Um bom exemplo deste tipo de interação são os comentários nos blogs. A interação mútua é uma interação mais livre, cuja relação se dá entre os interagentes em um dado momento. Chats e serviços de mensagem instantâneos são exemplos de interação mútua.

A vantagem da interação mediada por computador é que essa é uma característica da internet, onde pessoas que pouco conhecemos, amigos recém adicionados, têm acesso ao nosso mundo "privado". (BARRERAS, 2010)

Atualmente, muitas organizações utilizam-se dos blogs corporativos, além de personalidades e políticos, que também utilizam os blogs para interagir com os públicos e muitas vezes, apresentar a sua versão dos fatos publicados nos meios de comunicação tradicionais.

Os movimentos de adesão de sujeitos políticos às redes sociais da Internet podem ter várias interpretações. O desejo de maior aproximação, interação com os 
cidadãos, demonstrar maiores cotas de transparência e revelar, sem o filtro dos meios de comunicação de massa ou mesmo dos canais oficiais de comunicação dos poderes, as iniciativas, comportamentos e reflexões que considere pertinentes. Além disso, existe a possibilidade de construir reputação e imagem mesclando um perfil administrativo, realizador, de trabalho permanente, ao lado do perfil mais humano, pessoal, amistoso e familiar num cenário que valoriza a exposição da intimidade. (BARRERAS, 2010)

Em um universo tão grande de blogs, é necessário utilizar alguma estratégia específica, ou ter alguma característica peculiar para chamar atenção da blogosfera. No caso deste trabalho, a estratégia analisada foi a prestação de contas como forma de atrair leitores e se aproximar dos públicos de interesse.

\section{A Deputada Federal manuela D'áuila}

Manuela D’ávila tem 29 anos, é gaúcha, Deputada Federal pelo PCdoB - RS e jornalista formada pela PUC - RS. Foi no movimento estudantil que iniciou sua carreira na política, filiando-se à União da Juventude Socialista (UJS). Dois anos mais tarde iniciava na política partidária, filiando-se ao Partido Comunista do Brasil.

Após ser vice-presidente da União Nacional dos Estudantes (UNE) e Diretora Nacional da UJS foi eleita vereadora de Porto Alegre em 2004, fato que a tornou a vereadora mais jovem da história da cidade. Em 2006 candidatou-se a Câmara dos Deputados e foi a Deputada mais votada do Rio Grande do Sul, com 271.939 votos.

Em 2009 após ser indicada ao Prêmio Congresso em Foco pelos jornalistas foi eleita, pelos internautas, a parlamentar que melhor representa a população na Câmara.

Em 2010 candidatou-se à reeleição para o cargo de Deputada Federal e obteve mais um recorde - 482.590 votos - sendo a Deputada mais votada da história do Rio Grande do Sul e uma das mais votadas do país.

Na Câmara, Manuela é presidente da Comissão de Direitos Humanos e Minorias e faz parte das frentes parlamentares do esporte, em defesa da liberdade na internet e pela cidadania LGBT.

Em pesquisa divulgada pelo Departamento Intersindical de Assessoria Parlamentar (DIAP) foi apontada como parlamentar em ascensão na Câmara. Também foi apontada pela 
Revista Época como uma das 40 personalidades com menos de 40 anos mais influentes do Brasil.

Como detalhes desta pequena biografia mostram, Manuela é jovem, conhecedora e adepta das novas tecnologias e entusiasta do poder da internet e das possibilidades que a mesma apresenta, inclusive sendo integrante da Frente Parlamentar em Defesa da Liberdade na Internet.

Para deixar ainda mais claro tal fato, trago uma transcrição de um vídeo postado no Youtube, no qual Manuela fala sobre a internet

Com a internet nós sabemos o que acontece no mundo inteiro e temos a possibilidade de interferirmos nessa realidade, de nos atualizarmos e atualizarmos os outros. Com a internet nós não dependemos mais dos grandes veículos de comunicação pra nos dizerem aquilo que é importante. Nós podemos selecionar aquilo que é importante e conversar com os nossos colegas. E eu acho que a juventude tem feito no mundo inteiro da internet uma ferramenta de libertação. É importante dizer: a gente não inventa um mundo na internet, mas a gente pode transportar o mundo real lá pra dentro e fazer ali de dentro um espaço pra lutar pra que o nosso mundo aqui fora seja melhor. Como? Interagindo com as pessoas, denunciando com as pessoas, fazendo do nosso tempo tão escasso, cada vez mais escasso, também um tempo de luta pela transformação social. Acho que a gente ainda vincula muito a internet à diversão, mas a internet também é uma ferramenta de luta pra mudar o mundo pra melhor. (D’ÁVILA, 2011)

Consciente da importância de se comunicar por estes novos meios, a Deputada utiliza várias ferramentas de comunicação digital. Citarei aqui apenas as que possuem link no site oficial e que redirecionam para a ferramenta. São estas: MSN, Youtube, RSS, Blog do Mandato, Orkut, Facebook, hi5, Myspace, identi.ca, Sonico, Flickr e Formspring. Além destas, o site reserva um espaço para divulgar o twitter da Deputada - canto superior direito - onde as atualizações mais recentes ficam rodando, e um espaço para o blog pessoal - canto inferior direito - onde aparece o post mais recente. 


\section{O blog da Deputada manuela D'áuila}

O blog da parlamentar está hospedado no endereço

http://www.bolademeiaboladegude.blogspot.com, cuja plataforma é o blogger, serviço gratuito de hospedagem de blogs. Seu título é "Bola de meia Bola de gude - Há uma menina..." e é, segundo a própria autora explica em seu perfil, uma homenagem à famosa música de Milton Nascimento e Fernando Brant, com a qual ela se identifica.

O layout é baseado em tons pastéis: rosa bebê, azul claro e branco são as cores principais. Duas fotos complementam o design do blog, uma de Manuela quando criança e outra atual. No lado direito, abaixo do perfil, há um gadget que possibilita visualizar as postagens mais recentes do twitter da Deputada, proporcionando integração entre os meios.

No ar desde 25 de outubro de 2008 o blog conta com 1023 postagens, sendo 541, a maior parte deles, do ano de 2009.

No dia 26 de outubro de 2008, um dia após inaugurar o blog, Manuela fez uma postagem na qual explicava a proposta do blog

Por enquanto estou escrevendo esse blog para mim mesma. Quero fazer um teste antes de divulgá-lo, aos pouquinhos, para os amigos mais próximos. Quem será mesmo que tem paciência para ler meu blog pessoal? Minha vida política há de parecer mais interessante. Mas a Manuela política também é a menina que escreve no bloG (D’ÁVILA, 2011).

Essa característica mantém-se até hoje, tendo em vista que as postagens do blog são de temáticas bastante variadas. Dicas de música, de livros, poemas e desabafos pessoais mesclam-se com posts sobre a vida parlamentar, com opiniões a respeito de assuntos polêmicos e com explicações sobre do mandato. São estes últimos, os posts que se propõem a prestar contas a respeito do trabalho da Deputada que buscaremos, neste texto, realizar uma breve análise. 


\section{A prestação de contas no blog da Deputada manuela D'Áuila}

Analisaremos a seguir três postagens do referido blog. Todas as três relacionadas ao Deputado Jair Bolsonaro (PP-RJ) e suas declarações a respeito de mulheres negras que foram ao ar no programa Custe o Que Custar, da Rede Bandeirantes, no dia 28 de março.

Utilizamos o método da análise de conteúdo, por acreditarmos que ele atende de melhor forma os objetivos da pesquisa, já que segundo Babbie (1989) este é um método livre da intromissão no objeto de estudo, pois o pesquisador apenas analisa os dados já publicados, não podendo modificá-los. Coletamos os dados segundo as regras apontadas por Bardin (1988) e Barros e Targino (2000), principalmente a regra da pertinência, na qual fica estabelecido que os documentos devem ser adequados aos objetivos da pesquisa em todos os aspectos.

A primeira postagem é de 29 de março, um dia após a reportagem ir ao ar. A segunda postagem é de 5 de abril e a terceira de 28 de abril, exatamente um mês após a veiculação da reportagem.

Para analisar os posts realizamos uma primeira leitura do material, de onde extraímos três categorias principais: identificação e crítica ao preconceito; prestação de contas; proposições.

Abaixo apresentamos uma breve análise dos dados coletados.

\begin{tabular}{|l|lr|l|}
\hline Trecho & Postagem & Categoria \\
\hline $\begin{array}{l}\text { Dia carregado de luta pelo respeito às diferenças e pela } \\
\text { vida. }\end{array}$ & $\begin{array}{l}\text { Racismo é } \\
\text { crime para } \\
\text { todos! }\end{array}$ & $\begin{array}{l}\text { Identificação e crítica } \\
\text { aor preconceito; } \\
\text { Prestação de contas }\end{array}$ \\
\hline $\begin{array}{l}\text { Pelo fim da violência, da intolerância, Por um Brasil de } \\
\text { paz, colorido. }\end{array}$ & $\begin{array}{l}\text { Racismo é } \\
\text { crime para } \\
\text { todos! }\end{array}$ & $\begin{array}{l}\text { Identificação e crítica } \\
\text { ao preconceito }\end{array}$ \\
\hline $\begin{array}{l}\text { Vamos fazer do limão Amargo do preconceito de } \\
\text { Bolsonaro uma bela limonada contra o preconceito }\end{array}$ & $\begin{array}{l}\text { Racismo é } \\
\text { crime para } \\
\text { todos! }\end{array}$ & $\begin{array}{l}\text { Identificação e crítica } \\
\text { ao preconceito }\end{array}$ \\
\hline $\begin{array}{l}\text { O que pode ficar é a atenção e a luta para que } \\
\text { criminalizemos a homofobia }\end{array}$ & $\begin{array}{l}\text { Racismo é } \\
\text { crime para }\end{array}$ & $\begin{array}{l}\text { Identificação e crítica } \\
\text { ao }\end{array}$ \\
\hline
\end{tabular}




\begin{tabular}{|c|c|c|}
\hline & todos! & Proposições \\
\hline Relançamos num belo ato a frente parlamentar lgbt. & $\begin{array}{l}\text { Racismo é } \\
\text { crime para } \\
\text { todos! }\end{array}$ & Prestação de contas \\
\hline $\begin{array}{l}\text { Juntamos } 20 \text { deputados (...) e tomamos algumas } \\
\text { medidas: } \\
\text { 1. Encaminhamos ao Presidente da Câmara pedido para } \\
\text { que a corregedoria investigue e denuncie, se achar } \\
\text { correto, ao deputado para o Conselho de ética por } \\
\text { quebra } \\
\text { 2. Encaminhamos à Procuradoria geral da republica } \\
\text { para que tome as medida judiciais cabíveis. } \\
\text { 3.encaminhamos ao Conselho de direitos da pessoa } \\
\text { humana e secretaria da igualdade racial } \\
\text { 4. Pedido para que seu partido faça nova indicação para } \\
\text { a Comissão de Direitos Humanos. }\end{array}$ & $\begin{array}{l}\text { Racismo é } \\
\text { crime para } \\
\text { todos! }\end{array}$ & Prestação de contas \\
\hline $\begin{array}{l}\text { Mas ao ofender uma mulher negra daquela forma ele } \\
\text { cometeu o crime de racismo }\end{array}$ & $\begin{array}{l}\text { Racismo é } \\
\text { crime para } \\
\text { todos! }\end{array}$ & $\begin{array}{l}\text { Identificação e crítica } \\
\text { ao preconceito }\end{array}$ \\
\hline $\begin{array}{l}\text { Como militante comunista, como jornalista, como } \\
\text { brasileira, jamais defenderia qualquer atentado ao } \\
\text { direito que todos temos de nos expressar. }\end{array}$ & Simples assim & Proposições \\
\hline $\begin{array}{l}\text { Quando vedamos o anonimato estamos proibindo } \\
\text { alguém de se manifestar? Não!!! Estamos apenas } \\
\text { pedindo que essa pessoa assuma a responsabiliade pelo } \\
\text { que diz. }\end{array}$ & Simples assim & Proposições \\
\hline $\begin{array}{l}\text { Enquanto eu presidir a Comissão Bolsonaro não } \\
\text { ofenderá Jean Willis ou qualquer outra pessoa. }\end{array}$ & $\begin{array}{l}\text { Simples assim } \\
2\end{array}$ & $\begin{array}{l}\text { Proposições; } \\
\text { Identificação e crítica } \\
\text { ao preconceito }\end{array}$ \\
\hline $\begin{array}{l}\text { Ontem foi apenas isso que aconteceu na Comissão } \\
\text { Direitos Humanos. }\end{array}$ & $\begin{array}{l}\text { Simples assim } \\
2\end{array}$ & Prestação de contas \\
\hline
\end{tabular}

Tabela 1: Categorização dos posts. Elaborada pelas autoras 


\section{Considerações finais}

Esta breve reflexão nos possibilitou observar que a internet é ferramenta primordial nesta nova configuração de esfera pública, e, mais primordial ainda na transformação dos processos de participação política que ocorrem na esfera pública interconectada. Como bem disse Gomes (2005), é necessário que se criem modelos alternativos de democracia e a internet deve ter um papel fundamental na implementação e funcionamento destes novos modelos, já que eles só terão eficácia e serão diferentes realmente se tiverem participação de um grande número de pessoas.

As possibilidades tecnológicas nos colocam diante de uma nova revolução comunicativa que só tem sentido se revolucionar as formas de comunicar do homem e as apropriações que fazemos dos meios. Com isso, é importante analisar os fenômenos que ocorrem nas diversas instâncias da vida e hoje estão no ambiente digital, através das redes sociais e blogs.

Como o foco primordial de nossas análises é verificar a prestação de contas realizada através do blog, acreditamos que não somente os dados que foram colocados nesta categoria servem como prestação de contas. Saber, por exemplo, o posicionamento da Deputada com relação às declarações de Bolsonaro e também suas proposições a respeito de vida e de mandato pode servir como forma de prestar contas de seu trabalho à população. Prestação de contas essa que auxilia a transparência e que acreditamos ser importante tanto no âmbito estratégico, pois isto pode ser visto como um aspecto positivo pelos eleitores, como nas proposições referentes ao papel de suma importância que a comunicação pública assume na composição do processo político brasileiro.

Podemos dizer que a prestação de contas ou accountability é uma exigência da atual democracia, pois possibilita que o cidadão acompanhe as ações dos políticos e, através do monitoramento, até mesmo controle os gastos públicos. Trata-se de uma categoria normativa que foi viabilizada pelo cenário das redes sociais digitais e que tem o poder de incidir na avaliação e na visibilidade de políticos e gestores públicos. 


\section{Referências}

BARRERAS, S. E. O. B de. Ubiquidade na rede: os blogs pessoais para a intervenção de sujeitos políticos no espaço público. In: XIX COMPÓS, 2010, Rio de Janeiro - RJ.

BARICHELLO, Eugenia Maria Mariano da. Campo midiático, opinião pública e legitimação. In: Comunicação e Cultura Midiática. Santa Maria: UFSM, 2003.

DI FELICE, Massimo. Do público para as redes: A comunicação digital e as novas formas de participação social. São Caetano do Sul: Difusão, 2008.

GOMES, Wilson. A democracia digital e o problema da participação civil na decisão política. In: Revista Fronteiras, vol. VII, n.3. São Leopoldo, 2005.

HABERMAS, Jürgen. Mudança estrutural da esfera pública: Rio de Janeiro: Tempo Brasileiro, 2003.

KERCKHOVE, Derrick. Da democracia a Ciberdemocracia. In: DI FELICE, Massimo. Do público para as redes: A comunicação digital e as novas formas de participação social. São Caetano do Sul: Difusão, 2008.

JENKINS, Henry. Cultura da Convergência. 2ed. São Paulo: Aleph, 2009.

PRIMO, A. Interação mediada por computador: comunicação, cibercultura e cognição. Porto Alegre, Sulina, 2007.

SILVA, Daniela Bezerra da. Transparência na Esfera Pública Interconectada. São Paulo, 2010. Dissertação (mestrado em Comunicação Social - Processos Midiáticos: Tecnologia e Mercado) - Faculdade Cásper Líbero, Programa de Pós-Graduação em Comunicação Social.

Biografia de Manuela D’ávila. Disponível em http://www.manuela.org.br/biografia. Acessado em 25 de julho de 2011.

Blog da Manuela. Disponível em http://www.bolademeiaboladegude.blogspot.com. Acessado em 25 de julho de 2011. 